bated by the Central Committee for Hospital Medical Services this week, with particular reference to the manpower projection figures which were originally supplied by the Department as a companion to its original document (Supplement, $6 \mathrm{De}$ cember, pp. 55 and 56). If the recommendations of the progress report and the manpower projection are accepted there will be 2,000 consultants forced on the Health Service and 2,000 junior doctors will be phased out of it by 1978 .

The problem of the "registrar bulge" requires special consideration by consultants and staff in the regional hospitals, where staffing is presently at the minimum required to maintain essential work. Staffing requirements vary with the specialty. General principles of staff changes cannot be applied to all specialties in precisely the same way.

Before the profession accepts any new proposals these must be seen to be sensible and rational, and sufficient times must be given to discuss them before making decisions. Junior staff should be reduced where their numbers are excessive, but not necessarily as an overall countrywide measure. More consultants should be appointed where they are needed, and where facilities and junior staff exist, and the grade not diluted in a "blunderbuss" manner.

We will not be rushed into accepting a series of senseless generalizations so typical of an expanding bureaucracy.-I am, etc., JoHN J. SHIPMAN. Member, Negotiating Subcommittee of the C.C.H.M.S.

Letchworth

1 Responsibilities of the Consultant Grade. Department of Health and Social Security, Departmen of Health for Scotland. London, H.M.S.O.,
1969 .

\section{General Practitioners and the District Hospitals}

SIR,-The construction of your leading article on "General Practitioners and the District Hospitals" (3 January, p. 2) was fascinating. The opening paragraph of the article started with an apparent understanding of the problem, and clearly stated two very good reasons for the provision of generalpractitioner hospital beds. I quote: "The fact that the general practitioners in Great Britain, unlike many colleagues overseas, do not normally enjoy direct access to beds in major hospitals has often been cited as an important cause of emigration. Not surprisingly they have fought long and bitterly for this right, for most were trained exclusively in a hospital environment where the possession of beds was equated with higher status."

As one progressed through the article, hope faded and reality appeared. Various reasons are put forward why such a facility cannot be provided. In the concluding paragraph the voice of the established consultant breaks through with the bald statement that "it may be unrealistic to believe that general practitioners can or will always want to make more than a marginal contribution to staffing the hospital service. Perhaps a better form of participation may come in a way least discussed at the moment-namely, in situations where the family doctor can offer the hospital team a skill based on his special knowledge and experience."

Surely this misses the whole point, or does it? The point is that general practitioners must be allowed to care for their patients themselves to the limits of their capabilities. If these limits are never allowed to be extended, then these limits will automatically contract. The literature abounds with statements and reasons why the family doctor should be given the privilege of his own hospital beds. Some of these statements were made by those who saw the writing on the wall and emigrated. For those of us that remain and care about standards of medicine we wish to offer our patients it would seem that reasoned argument and statement of needs alone is not enough. Now that the structure of the staffing of the National Health Service, the responsibility of the consultant grade, and medical education in general are all in the melting-pot we must make such a noise that our voice is heard. And if the voice is not listened to the noise must get louder.

I feel that your article started off by stating what we want, but finished up by telling us what we are likely to get. Indeed, I hope that this will not be so.-I am, etc.,

Bury, Lancs.

Simon Jenkins.

SIR,-It would be interesting to know, and try to understand, Mr. Richard Crossman's motives for threatening to ban private insurance for medical treatment. To do so would at once increase the size of the large queues already waiting for National Health Services. Ordinary people would think that the way to reduce waiting-lists would be to provide more services-beds, operating facilities, equipment, technicians, and, most of all, nurses.

If $\mathrm{Mr}$. Crossman really practises what he preaches-never, for example, travelling by car on account of getting to his destination more quickly and more comfortably than people who wait in bus queues-one must admire him, even while disagreeing with him.-I am, etc.,

Cambridge.

E. V. Bevan.

\section{Private Medical Insurance}

SIR,-I am surprised that so little comment has arisen in the B.M.f. as a result of Mr. Crossman's remarks on the effects of private medical insurance. A misconceived statement on a subject pertaining to medicine one would expect to arouse spirited protest. That it was bristling with dogma culled from years of his party's traditional hostility to "privilege" arising from obsolete class attitudes and the apparent wish to reduce everyone to an amorphous uniformity is to be expected. This may explain the profession's comparative indifference. However, unless we as a profession make it known that we disagree with statements such as this, a Minister like Mr. Crossman might quite reasonably assume we agree with them

There is of course no evidence that private treatment in private beds or consultingrooms produces longer N.H.S. waiting lists. Possibly it fractionally reduces them; but this is not provable either. It could be argued that abolition of private insurance would result in fewer consultants taking part-time posts because of the reduction in private work which might follow. This would be to assume that N.H.S. departments could cope with extra sessions and so increase the turnover of N.H.S. patients and usefully employ the extra time available from the consultants. It seems unlikely that operating theatres and $x$-ray departments in most hospitals could be stretched beyond the present limitations imposed by ancillary staff shortages, to use two examples only. In any case, what part-time consultants do in their sessions which are not devoted to the N.H.S. is really none of Mr. Crossman's business.

Mr. Crossman's remarks, although directed at the medical insurance firms, are

\section{Vocational Training for General Practice}

SIR,-Thirty-five years ago I did two years in hospital and a year as an assistant before entering general practice. At that time, because of economic pressures, some had to go straight into practice after passing their finals. Preregistration posts have been made practicable by salaries for house jobs more adequate than in my day.

Improvements in curgery accommodation during the past 20 years have not resulted from compulsion, but by virtue of competition and because for some there has been encouragement with grants and loans. The more general use of ancillaries has not resulted from compulsion but because grants

Men and women who qualify in medicine have a sense of responsibility or they would not trouble. A "vocation" is an inner light which may be present or may be acquired, but which cannot be taught. The good jobs will always go to the suitable men and women who have fitted themselves for them.

What is wrong about the present proposals is the element of compulsion. A doctor is essentially an individualist, who will be the better for going his own way. It is a mistake not to give the maximum freedom and encouragement. Competition, a special interest, the desire for self-improvement, the inner light-these are the keys, not compulsion. Wisdom is better than mere learning, kindness than high ability, willingness to serve than organization. Only the years can bring the maturity of judgement and character which make a whole man.-I am, etc.,

GORDON SCOTT. have been made available. 